\title{
Miradas historiográficas sobre los obispos. Abordajes de un sujeto histórico complejo a través de la historiografía argentina en el periodo colonial y temprano-independiente
}

\author{
Historiographical points of view the bishops. Approaches to a complex \\ historical subject through Argentinian historiography in colonial and \\ early independent times
}

\author{
María Laura Mazzoni \\ mazzonilaura@gmail.com \\ Doctora en Historia \\ Instituto de Historia Argentina y Americana "Dr. E. Ravignani" \\ Millán, 1136 \\ Mar del Plata - Provincia de Buenos Aires \\ Argentina
}

\section{Resumen}

La historia social de la iglesia en Argentina se ha desarrollado con mucho ímpetu a partir de la década de 1990, de la mano de la ampliación y proliferación de la producción historiográfica académica en el país. Este trabajo se propone, en primer término, dar cuenta de ese recorrido centrándose en la historia de la jerarquía eclesiástica y atendiendo a las nuevas preguntas, y los cambios temáticos y analíticos de los especialistas de este campo. En segundo lugar, y a modo de ejemplo de lo antedicho, este texto tiene por objetivo puntualizar la distancia que marca la historiografía actual sobre el gobierno episcopal en diócesis de antigua colonización, como la de Córdoba del Tucumán, con respecto a diócesis "de frontera" en el espacio rioplatense a fines del siglo XVIII y principios del XIX.

\section{Palabras claves}

Historia social; Historiografía argentina; Siglo XIX.

\begin{abstract}
Church social history in Argentina has developed vigorously since the 1990s along with the expansion of the academic historiographical production in the country. This article proposes, in the first place, to examine these studies focusing on the history of ecclesiastical hierarchy and taking into account new questions, subjects and analytical changes in this field. In the second place, and as an example of these innovations, this paper aims to specify the distance held by current historiography about the episcopal government in ancient colonized dioceses, like Córdoba del Tucumán, in relation to "border churches" in the Río de la Plata region between the last decades of the $18^{\text {th }}$ century and the first half of the $19^{\text {th }}$ century.
\end{abstract}

Keywords

Social history; Historiography of Argentina; $19^{\text {th }}$ century.

Recibido el: 28/7/2016

Aceptado el: 5/8/2016 
La ampliación y proliferación de la producción historiográfica académica en la Argentina acompañó los caminos de la apertura democrática. El retorno de numerosos investigadores al país, un contacto más asiduo con centros de investigación prestigiosos, y la multiplicación de reuniones científicas de historiadores dieron como resultado una mayor profesionalización de la disciplina, y la aparición de nuevos temas y horizontes historiográficos.

La historia social de la iglesia en Argentina se ha desarrollado con mucho ímpetu a partir de la década de 1990, con la incorporación de historiadores que en muchos casos se nutrieron y formaron en centros de investigación europeos que ya abordaban cuestiones eclesiásticas desde la historia social, política y económica, tanto para el periodo colonial como para los siglos XIX y XX. En este sentido, la historia colonial, y la de los primeros años independientes se nutrió, a partir de entonces, de nuevas preguntas y problemas históricos sobre temas y documentos, que completaron y complementaron aquellos nudos problemáticos que habían sido objeto de una importante renovación desde la historia política. Es decir, la cuestión de las reformas borbónicas, la retroversión de la soberanía a partir de la independencia, la participación de diferentes actores en el proceso revolucionario, o el papel de la mujer en el periodo colonial y decimonónico, por nombrar solo algunos problemas históricos, fueron atendidos ahora desde la historia de la iglesia. Esto se vio plasmado en un importante número de tesis doctorales y libros que materializaron este derrotero (AYROLO 2007; BARRAL 2007; DI STEFANO 2004; FOGELMAN 2000; FRASCHINA 2010; GALLO; CALVO y DI STEFANO 2002; LIDA 2006; PEIRE 2000).

Este trabajo se propone, en primer término, dar cuenta de las líneas generales de investigación que abordaron el estudio de los obispos como actores claves del periodo, y del episcopado y la diócesis como institución para el periodo colonial y temprano independiente. En segundo lugar, el trabajo se propone cuestionar algunas generalizaciones que se han hecho sobre el gobierno y el accionar de los obispos en los diferentes obispados del territorio del ex Virreinato del Río de la Plata. Basándonos en las diferencias existentes entre una "iglesia de frontera" como la porteña, y obispados en espacios de antigua colonización, como el tucumano, marcaremos un contrapunto con estas visiones.

Nos centraremos en la diócesis de Córdoba del Tucumán. Este espacio tiene una historia de antigua colonización en el área tucumana. Creada en 1570, la Diócesis del Tucumán cuya sede primera había sido Santiago del Estero, trasladó en 1699 su sede diocesana a Córdoba. Córdoba pasó a ser entonces cabeza del obispado. La ciudad albergaba la catedral, y poseía una casa de altos estudios que otorgaba títulos universitarios por concesión pontificia y real, fundada a principios del siglo XVII por la Compañía de Jesús, única institución que otorgaba títulos de grado en la región. Por otra parte, Córdoba tenía dos colegios convictorios y cuatro conventos que marcaban la presencia de las órdenes religiosas: jesuitas, franciscanos, dominicos y mercedarios. Existían, además, dos conventos de monjas, el de las teresas y el de las catalinas. Se trata de un espacio jurisdiccional muy importante, dotado de una estructura eclesiástica antigua, y que por otra parte, albergaba la sede de la Gobernación 
Intendencia de Córdoba desde 1783. En 1806 la Diócesis del Tucumán fue desmembrada y se crearon dos obispados nuevos. El de Salta, y el de Córdoba que contenía a las jurisdicciones de Córdoba y La Rioja y a la que se sumaron las tres jurisdicciones cuyanas (San Juan, San Luis y Mendoza), que antes habían pertenecido a la Diócesis de Santiago de Chile.

\section{Los obispos en el centro del análisis de la historia de la Iglesia en Argentina}

Si bien la historia eclesiástica en Argentina se consolidó como un campo en sí mismo gracias a las contribuciones de la historia social, política y cultural (AYROLO 2007; BARRAL 2007; DI STEFANO 2004; DI STEFANO; ZANATTA 2000; PEIRE 2000), los estudios desde el ámbito confesional (por citar solo algunos ejemplos: BRUNO 1970; TONDA 2009) o aquellos centrados en la historia eclesiástica desde una mirada más institucional (DELLAFERRERA 1999; LEVAGGI 2003; MAEDER 2003; MARTÍNEZ DE SÁNCHEZ 2006; PEÑA 1994) fueron imprescindibles para dicho proceso, ya que brindaron un corpus bibliográfico que abrió las puertas a nuevas fuentes -eclesiásticas- y preguntas que se tomaron como punto de partida. Por ello, el estudio de las administraciones diocesanas precisaron y precisan de la consulta a estas obras pioneras.

La Historia de la Iglesia en Argentina, de Cayetano Bruno, conforma un trabajo monumental que, entre otros temas, aborda la cuestión de la gestión eclesiástica de los obispos (BRUNO 1970). ${ }^{1}$ La amplia variedad de archivos consultados por Bruno es una valiosa guía para comenzar cualquier investigación

116 relacionada con la iglesia en el espacio rioplatense. El autor no sólo atendió al origen, formación y trayectoria de los obispos de las diócesis existentes desde la creación de la primera mitra en el territorio en 1570, sino que también prestó atención a su actuación política. Su análisis se centra en una mirada institucional, a través de la cual subyace una puja constante entre el poder civil y el religioso en detrimento de este último. Veamos un pasaje de la Historia de la Iglesia en Argentina, que ilustra la adjetivación propia del discurso de los estudios confesionales cuya carga valorativa - positiva- hacia los eclesiásticos es propia de una reconstrucción biográfica arquetípica (ROMERO 2008). Estos textos intentan mostrar a través de las vidas de los prelados, un ideal, un modelo, portaestandarte de los valores de la fe católica:

¿Tenía algún fundamento esta reiterada acusación denigrativa del buen nombre de los referidos clérigos y del Obispo? Ninguno. Lo verá el lector. Y da grima comprobar que casi siempre este cargo fuese pantalla de ocultos manejos, y que se tildase con él generalmente a las personas más sensatas y virtuosas de la sociedad de entonces (BRUNO 1970, v. VIII, p. 250).

En el mismo registro podemos mencionar El Obispo Orellana y la Revolución, de Américo Tonda (TONDA 2009), fuente de consulta obligatoria para el estudio de este prelado en particular y del proceso revolucionario que se inicia a pocos

\footnotetext{
${ }^{1}$ La obra de Cayetano Bruno Historia de la Iglesia en Argentina consiste en 12 tomos que fueron publicados entre 1966 y 1981. La fecha de 1970 corresponde a los tomos VIII, IX y X que concentran el análisis del periodo tardocolonial y temprano-independiente.
} 
años de su arribo a Córdoba. En este caso, Tonda destaca la figura de quien fue el último obispo español en llegar al Río de la Plata y el primero de la diócesis cordobesa creada en 1806. Retoma sus atributos y sus particularidades y a partir de allí analiza su actuación frente al proceso de independencia. Su relato imprime una mirada condenatoria al proceso revolucionario, y la gestión diocesana es observada como una carrera de obstáculos frente a las trabas impuestas a Orellana por el nuevo gobierno.

Por supuesto que en esta literatura histórica los méritos religiosos son resaltados por encima de la actuación política de los sacerdotes o prelados, en sintonía con un clima de época de la décadas de 1970 y 1980, cuando la participación política de los sacerdotes no gozaba ya de consenso dentro de la iglesia católica. Así, Nelson Dellaferrera ha descrito al provisor del obispado de Córdoba, Gregorio Funes -destacado sacerdote de la década de 1810 que estuvo cerca de lograr la mitra cordobesa- rescatando los rasgos de su actuación sacerdotal pese a haberse involucrado en las lides de la política. Funes era, según Dellaferrera, "un juez recto, probo, perspicaz e inteligente, y esto por encima de su actuación política". Y de Benito Lascano, vicario apostólico y luego obispo auxiliar de Córdoba, destacaba "la fuerza y la reciedumbre [...], aunque no siempre fue capaz de mantenerse fuera de la lucha política de su tiempo [...]" (DELLAFERRERA 1996, p. 118).

Esta mirada condescendiente con los actores eclesiásticos fue superada, en un principio, por la proliferación de estudios sobre el episcopado en las monarquías ibéricas para el caso español, novohispano y portugués, con mayor profundidad que para el espacio rioplatense. José Manuel Cuenca Toribio ha rastreado y estudiado al episcopado español desde fines del Antiguo Régimen hasta mediados del siglo XX. Para el periodo antiguoregimental, el autor resaltó el peso de la política y los intereses personales en los nombramientos de obispos del periodo (CUENCA TORIBIO 1976). Trabajos como el de Barrio Gozalo sobre los obispos españoles a lo largo del siglo XVI al XIX muestran un perfil sociológico del episcopado en la península mediante el método prosopográfico (BARRIO GOZALO 2000). Estas investigaciones presentan aspectos como el origen o la formación de los candidatos al episcopado español. Otro ejemplo lo constituye el trabajo que realizaron Castañeda y Marchena para los obispos de Indias desde 1500 a 1850, una especie de diccionario biográfico donde incluyeron datos de la trayectoria de los prelados en la estructura eclesiástica (CASTAÑEDA DELGADO; MARCHENA FERNÁNDEZ 1992). En los últimos años, Andoni Artola ha analizado el acceso al episcopado en la España moderna aplicando el estudio de redes a este tema. El autor destaca en sus escritos la importancia de las dinámicas relacionales internas del alto clero para el acceso a una mitra. Los canales institucionales de selección de candidatos para mitras fueron suprimidos hasta pasar a ser, en 1793, prácticamente una decisión personal del monarca o de su principal ministro, y esto fue utilizado como un mecanismo arbitrario para premiar a obispos cercanos al monarca. Sus estudios demuestran cómo la selección de los obispos peninsulares y americanos estuvo regida por una tendencia episcopalista dentro de la jerarquía eclesiástica (ARTOLA RENEDO 2013; 2014). 
En el caso de Portugal, José Pedro Paiva ha discutido la idea de que el regalismo pombalino arremetió contra la voluntad de la jerarquía eclesiástica portuguesa. Por el contrario, sostiene el historiador, la embestida regalista fue consumada con el apoyo de un clero que compartió estas doctrinas y que en el plano práctico se encargó de viabilizarlo e instaurarlo (PAIVA 2006).

En otros espacios, la actuación de los obispos en contextos de reforma o revolución ha sido estudiada atendiendo a su trayectoria y formación, sus vinculaciones sociales y políticas, y su labor pastoral (FERNÁNDEZ MELLÉN 2014; HERNÁNDEZ GARCÍA 2008). En lo que se refiere a las guerras de independencia americanas, el episcopado ha sido estudiado como un actor clave de la oposición a estos procesos políticos emancipatorios. En general, la jerarquía eclesiástica fue analizada teniendo en cuenta su mayoritaria adhesión a la causa realista (AMORES CARREDANO 2009).

En Nueva España, donde las instituciones eclesiásticas tenían un peso social y político, pero sobre todo económico, mucho más palpable, Leticia Puente ha observado que los prelados, en tanto hombres políticos, hicieron uso de estrategias comunes a todos los grupos de poder del período analizado. No hay que desdeñar "el importante papel desempeñado por las redes privadas de lealtad personal que se tejían en consejos, audiencias y cancillerías" en pos de la obtención de una mitra (PÉREZ PUENTE 2012, p. 162). En este sentido, la tarea reformadora de los obispos regalistas en el siglo XVIII ha sido vista como un incremento significativo de la supervisión de prácticas por parte de los funcionarios reales

118 (CONNAUGHTON 2008, p. 191). Los obispos fueron considerados ejes mayores de la transformación (CONNAUGHTON 2008, p. 193).

Los aportes desde la historia social y cultural han permitido prestar atención a la institución eclesiástica como un espacio de poder y sociabilidad atravesado por las relaciones personales, la política, la economía y hasta la guerra, y a los obispos y clérigos, como hombres políticos (SALVADOR AGUIRRE 2010).

La jerarquía eclesiástica no ha sido estudiada en forma tan exhaustiva como el clero en general, tanto secular como regular, en la historiografía argentina. Algunos estudios han atendido a la formación del clero, su extracción social, su participación en política (AYROLO 2000, 2001, 2001, 2006, 2007, 2011; AYROLO; BARRAL 2011; AYROLO; CARETTA 2003, 2009; BARRAL 2007, 2009; DI STEFANO 1997, 2000, 2000, 2004, 2013; PEIRE 2000; TROISI-MELEAN 2008; TROISI MELEAN 2006), y su vínculo con la feligresía (AYROLO 2006; AYROLO; CARETTA 2003; MALLO 1995, 2000; PELAGATTI 2008). En definitiva, se ha subrayado el papel central del clero dentro de la sociedad, en el ámbito urbano, y también en el rural, donde sus miembros actuaron como jueces (BARRAL 2003), maestros (BARRAL 2007) y mediadores (BARRAL 2009; BARRAL; DI STEFANO 2008).

El clero secular ha sido, por su parte, objeto de una revisión profunda a partir de la renovación historiográfica señalada. Roberto Di Stefano ha estudiado el clero secular de Buenos Aires y advirtió que este estamento religioso fue el mayor beneficiado por la expulsión de la Compañía de Jesús de la monarquía hispánica, a raíz de la cual fue adquiriendo un creciente prestigio y poder (DI STEFANO 2004, p. 97). Valentina Ayrolo señaló que la participación del clero 
secular en la construcción de la nueva entidad política durante las autonomías provinciales en la década de 1820 encontró a los clérigos "proporcionando los fundamentos teóricos al nuevo sistema, colaborando en su legislación y resolviendo problemas de gobierno, como también legitimando lo actuado por sus pares civiles" (AYROLO 2007, p. 172).

Particularmente en el caso de los obispos, la historiografía reciente ha destacado su función en tanto mediador entre los fieles y la corona, y el intento de la monarquía española de convertir al obispo en el siglo XVIII, en funcionario al servicio del Rey (AYROLO 2007; BARRAL 2007; CONNAUGHTON 2008; DI STEFANO 1999; MAZZONI 2013, 2013, 2015; TAYLOR 1999; URQUIZA 1993).

Desde la historia social y cultural, la historiografía argentina ha reflexionado sobre las instituciones religiosas y sus actores. Peire ha estudiado las instituciones eclesiásticas y el imaginario cultural desde la expulsión jesuita hasta el periodo revolucionario en el Río de la Plata, y ha subrayado que "la sociedad tardocolonial era incapaz de disolver el núcleo y la estructura específicamente clerical, y más en concreto el clero, que formaba en el imaginario colonial, aquella parte de la sociedad a la que el resto miraba como un 'espejo' donde creía debía verse reflejado el ideal de persona y sociedad" (PEIRE 2000, p. 192). En El Taller de los Espejos, el autor demuestra la importancia de las órdenes regulares en el periodo temprano colonial en la evangelización que acompañó el proceso de conquista, y en el ámbito de la educación. En los siglos XVI y XVII, las órdenes regulares tenían una mayor presencia en América, y ocupaban espacios de poder que el clero secular intentaba disputarles. Esto se expresó, por ejemplo, en el origen de los obispos durante este período. Según el autor, en el siglo XVI, de 171 obispos de América, "108 fueron religiosos y sólo 63 seculares" (PEIRE 2000 , p. 64). Entre los motivos por los cuales la corona prefería presentar prelados regulares, el Consejo de Indias esgrimía la labor evangelizadora, el buen tratamiento que proferían a los indígenas, la humildad y el desapego hacia los bienes materiales que mostraban los religiosos (PEIRE 2000, p. 65). En el período tardocolonial, los criterios de selección de candidatos para una mitra habían cambiado y el clero secular primaba entre los candidatos a ocupar mitras americanas (MAZZONI 2013).

En relación con la jerarquía eclesiástica, Di Stefano sostiene que el progresivo dominio del clero secular generó tensiones con las intenciones de la metrópoli de conservar su prerrogativa y soberanía sobre la administración diocesana. Los seculares de Buenos Aires, acostumbrados a autogobernarse por los prolongados periodos de vacancia, ganaban cada vez más autonomía y esto chocaba contra los intereses de la corona. "La mayor parte de los clérigos servía beneficios que no eran de colación episcopal, sino de patronato laico, o se desempeñaba en puestos de la administración colonial ajenos a la órbita del obispo" (DI STEFANO 2004, p. 39). Estos datos le permiten al autor sostener que en la diócesis porteña los obispos no tenían una presencia fuerte, y las tensiones con el clero local acentuaban esa debilidad (DI STEFANO 1999; 2013).

La actuación de los obispos del ex virreinato del Río de la Plata en torno al ejercicio del patronato luego de la Revolución ha sido revisada también 
por la historiografía argentina y americana en general (AYROLO 1996; ENRÍQUEZ 2008; LIDA 2004; MARTÍNEZ 2013). Ayrolo muestra cómo el poder revolucionario tuvo que hacer frente no sólo al contexto de guerra, sino a la oposición de los prelados a reconocer al nuevo poder soberano (AYROLO 1996). Y en este mismo camino, Martínez analiza la trayectoria de los obispos que ocupaban las mitras de Salta, Córdoba y Buenos Aires y los diferentes comportamientos seguidos por los prelados en ese contexto (MARTÍNEZ 2013, especialmente cap. 2).

Los trabajos sobre prelados en Córdoba en el periodo tardocolonial y temprano independiente se han centrado en la formación y actuación de los últimos obispos coloniales y durante la década revolucionaria (BARRAL; DI STEFANO 1999; MAZZONI 2013; SÁNCHEZ PÉREZ 2014; TONDA 1973, 1973, 2009), y en su vinculación con la política local (AYROLO; MAZZONI 2013; MAZZONI; GÓMEZ 2015). En el caso del obispado de Córdoba del Tucumán, "la administración eclesiástica que llevaron a cabo los obispos moldeó la identidad -católica- de la feligresía cordobesa. La impronta diocesana formó parte de la construcción de un imaginario colectivo, en el que el sustrato religioso católico romano constituyó uno de los componentes fundamentales que caracterizaron al espacio y a sus habitantes, y los legitimaron. Esto fue posible mediante el trabajo realizado por obispos y clero en el sostenimiento de instituciones y valores fundamentales para la feligresía" (MAZZONI 2013, p. 304).

Conocemos aún muy poco sobre la relación entre las instituciones diocesanas

120 en el espacio rioplatense y las instancias de gobierno superiores. No hay, una historia del episcopado americano, y mucho menos de los obispados sufragáneos de la Arquidiócesis de Charcas de la que dependía Córdoba, en el periodo estudiado, que nos permita tener una visión de conjunto sobre los prelados que estudiamos. En ese sentido, la relación entre las diócesis y su sede arzobispal es en gran medida un terreno aun por explorar. En el caso de los gobiernos diocesanos, hemos estudiado los lazos existentes entre la arquidiócesis y su sufragánea de Córdoba a través de la trayectoria de los obispos tardocoloniales. En el siglo XVIII, el camino entre una diócesis altoperuana o el arzobispado charqueño y la mitra cordobesa era un derrotero natural y asiduo. Muchos obispos cordobeses obtenían, en premio a su labor, un ascenso a diócesis con mayores rentas en el espacio altoperuano de la misma provincia eclesiástica, o su coronación como arzobispo de Charcas, como en el caso de San Alberto en 1783 (MAZZONI 2013, cap. 1). Pero aun ignoramos en gran medida la relación entre los obispos rioplatenses y su arzobispo, y los mecanismos de control e instancias de gobierno de la arquidiócesis.

Tampoco se han investigado en profundidad los nexos entre las instituciones diocesanas y las órdenes regulares. Arena de negociación, conflicto e interacción continua, los cruces entre el clero secular y el clero regular a nivel institucional no han sido ampliamente explorados. Sí se han abordado, en este sentido, los conflictos que suscitaron estas interacciones, ya fueran en el ámbito universitario o en coyunturas críticas como la expulsión de los jesuitas de la monarquía española o la revolución de Mayo (BENITO MOYA 2011; LIDA 2006; LORANDI 
2008; TONDA 1973). Sin embargo, todavía es necesaria una revisión sobre esta fértil relación en el periodo colonial (MAZZONI 2016).

Por último, el vínculo entre las diócesis rioplatenses y la Santa Sede también exige nuevos análisis. Se ha estudiado con profundidad el ejercicio del Patronato, sobre todo luego de la ruptura de los lazos monárquicos (AYROLO 1996; MARTÍNEZ 2011, 2013), pero poco se conoce a cerca de la existencia de lazos entre el Papado y los gobiernos diocesanos que corrieran por caminos ajenos a la mediación real, como sí ha sido estudiado y demostrado para otras diócesis americanas (ALBANI 2008, 2012).

\section{La jerarquía eclesiástica en iglesias de antigua colonización}

Como vimos, el desarrollo de la historia social y de la historia de la iglesia en Argentina ha enriquecido el conocimiento que se tenía sobre las sociedades tardocoloniales y decimonónicas. En el caso del espacio cordobés, nuestro estudio se ha centrado en la gestión eclesiástica de los últimos obispos coloniales del más antiguo de los tres obispados del territorio que existían en 1806 -el de Córdoba del Tucumán fundado en 1570- (MAZZONI 2013). Analizamos la trayectoria, formación, las devociones que propiciaron y las prácticas religiosas que concibieron teniendo en cuenta el contexto político en el cual gobernaron la diócesis. Nuestra investigación también abarcó la vinculación del accionar de los prelados con la conformación de una identidad regional, que se erigió, a principios del siglo XIX, en estandarte de la religión católica de las Provincias Unidas del Río de la Plata frente a las reformas liberales en las que se embarcaron provincias como Buenos Aires, San Juan y Mendoza en la década de 1820.

Las conclusiones para el caso cordobés difieren de lo que se ha observado en el caso de la diócesis de Buenos Aires (DI STEFANO 1999; 2004; 2013; DI STEFANO; MARTÍNEZ 2011; LIDA 2004). Para el caso porteño, Di Stefano ha sostenido que las administraciones diocesanas a lo largo del siglo XVIII y la primera mitad del siglo XIX no tuvieron un peso significativo en el gobierno episcopal. Así, sostiene que "el gobierno natural de la Iglesia, sobre todo en el Río de la Plata, donde la presencia episcopal es tan irregular y las vacantes tan prolongadas, reside en el cabildo eclesiástico en representación del clero secular. Los obispos pasan [...]" (DI STEFANO 1999, p. 80).

La administración diocesana en el espacio cordobés da cuenta de una situación muy diferente. Las apreciaciones de la diócesis rioplatense se alejan de lo que acontecía en otras vecinas, como la de Córdoba, evidenciando a la diócesis porteña como una excepción, más que la norma. Valentina Ayrolo ha advertido ya sobre las diferencias entre la región del Tucumán y la rioplatense (AYROLO 2003; 2007). Sus estudios han demostrado el peso de la iglesia en el Tucumán, "no sólo porque fue la ordenadora del espacio social sino además porque actuó como mediadora, fuente de legitimidad, esencia misma del 'ser cordobés'" (AYROLO 2003, p. 179). Allí, el clero secular, y el regular gozaban de una escasa autonomía por sobre la jerarquía eclesiástica. En esto acordamos con Oscar Mazín quien destacó las diferencias estructurales que en el siglo XVII separaban a las diócesis novohispanas de las de las Indias meridionales, y señaló 
que las diócesis del espacio peruano se regían con una mayor centralización (MAZÍN GÓMEZ 2015).

La diócesis de Córdoba compartía una relación de larga data con las diócesis altoperuanas, y guardaba características que la semejaban a obispados con un historial y una experiencia en la administración diocesana muy antiguas; era, en suma, una "iglesia de vieja colonización" (AYROLO 2003, p. 184), que se distinguía de una "Iglesia de frontera" como se ha dado en llamar a las instituciones eclesiásticas coloniales porteñas (DI STEFANO 1997, p. 46). La diócesis del Río de la Plata, en tanto iglesia de frontera se alejaba de obispados de tradición, a veces milenaria, como las europeas, y "se encontraba periódicamente frente a la necesidad de crear nuevas estructuras pastorales y obligada por lo tanto a encontrar el personal dispuesto a hacerse cargo de ellas" (DI STEFANO 1997, p. 46).

En este sentido, el circuito de "pertenencia" del espacio cordobés, era aquel del Alto Perú, de la arquidiócesis de Charcas. Entre estos espacios había una tradición compartida que incluía el comercio, y la circulación de hombres. Los clérigos los transitaban portando experiencias y una identidad compartida. $Y$ lo más importante, la jerarquía eclesiástica era común en estas jurisdicciones eclesiásticas. Clérigos altoperuanos fueron premiados con la mitra cordobesa (como en el caso de Ángel Mariano Moscoso en 1789), y más frecuentemente los prelados cordobeses eran promocionados a diócesis con mayores rentas en el espacio altoperuano como una especie de compensación por las penurias pasadas en el obispado tucumano (este es el caso de Abad Illana, y el de Joseph Antonio de San Alberto por poner solo algunos ejemplos del período tardocolonial).

La jerarquía eclesiástica en espacios de antigua colonización formaba parte de la elite letrada de la comunidad, detentaba una posición de poder en tanto máximo exponente del clero diocesano y, en el período analizado, tuvo un activo papel en la defensa de la causa realista en las nuevas repúblicas que se constituían. Sin embargo, muchos pudieron mantenerse en sus puestos de jerarquía sin mostrar una adhesión sincera a la revolución. Tal es el caso de José Sebastián de Goyeneche, obispo de Arequipa desde 1817 a 1859. Goyeneche pertenecía a un linaje arequipeño con gran ascendente en la región. Y pese a su apoyo al bando realista, supo mantenerse en la mitra gracias a su gran habilidad para evitar un enfrentamiento directo con las autoridades revolucionarias. En 1859 incluso obtuvo el cargo de arzobispo de Lima (ROJAS INGUNZA 2007). También Pedro Gutiérrez de Cos, obispo de Huamanga, es considerado como uno de los representantes del "conservadurismo" en su defensa de las ideas monárquicas en el virreinato peruano (HERNÁNDEZ GARCÍA 2008). Gutiérrez de Cos tuvo que huir de su mitra en Huamanga hacia territorio aun controlado por la corona española. Su exilio y el apoyo a la causa realista le valió el nombramiento como gobernador eclesiástico de la mitra de La Habana y, poco después, con la sede de Puerto Rico. La misma postura fue compartida por Diego Antonio Navarro Martín Villodres, obispo de la diócesis de Concepción del Reino de Chile entre 1806 y 1816, y por Nicolás Videla del Pino. Navarro tuvo un destacado papel al frente del bando realista en Concepción, incluso reclutando tropa, mientras que 
Videla del Pino fue desterrado en 1812 por el General Manuel Belgrano por su comunicación con las tropas realistas del Alto Perú (AYROLO; CARETTA 2003; ENRÍQUEZ AGRAZAR 2005).

Los obispos de la diócesis cordobesa entre el fin del periodo colonial y el primer tercio del siglo XIX fueron muy activos en hacer visitas a toda la diócesis, para conocer a su feligresía, pero también para mostrar una presencia y autoridad real y para controlar al clero y a los fieles (MAZZONI 2015). Entre los años 1778 y 1836 se realizaron 66 visitas diocesanas en el obispado de Córdoba del Tucumán: San Alberto, 15; Moscoso, 39; Orellana, 11, y dos, durante el provisoriato de Lascano en 1827. Un ejemplo paradigmático son las numerosas visitas practicadas personalmente por el obispo Ángel Mariano Moscoso supervisando los curatos de la campaña donde se preocupó de reforzar la presencia de la Iglesia. En 1813, como resultado de la visita de Rodrigo de Orellana a la diócesis, el obispo escribía un informe donde mostraba con gran realismo la situación diocesana; aprovechó la oportunidad para realizar algunos reclamos al gobierno, con miras a lograr las mejoras que había ideado (AYROLO 2010).

Para el caso de Córdoba, en los años en los que el gobierno diocesano se encontraba en manos de un obispo, su conocimiento y experiencia eran la fuente principal de consulta para la resolución de cuestiones administrativas y para el correcto funcionamiento de la Audiencia episcopal. Sobre todo, desde mediados del siglo XVIII cuando la ausencia en la jurisdicción eclesiástica de concilios y sínodos implicó una mayor intervención y una vigorosa actividad legislativa por parte del episcopado (MAZZONI 2015). Ejemplo de esto fueron los consejos que se les solicitaban a los prelados sobre el ceremonial. Pero sobre todo, esta noción del obispo como fuente de legitimidad y, por ende, de consulta obligatoria puede verse en la constante relación de negociación entre el cabildo y el prelado. A modo de ejemplo, citamos el caso de la elección, por parte del cabildo, de Gregorio Funes como provisor de la diócesis en 1804 a la muerte del obispo Moscoso. Luego de las gestiones infructuosas que Funes llevó adelante para lograr la mitra cordobesa, decidió continuar peleando su lugar de provisor. Fue en 1804 cuando la elección realizada tuvo que ser ratificada -a pedido del cabildo y de Funes- por el obispo electo, Rodrigo Antonio de Orellana, quien aun estando en la Península fue consultado por el cabildo sobre la legitimidad de la elección. Por ello, sostenemos que si bien el capítulo catedral de Córdoba también representaba al clero local, gobernar con legitimidad fue, en el espacio cordobés al menos, muy importante y lo seguiría siendo a lo largo del período estudiado. Aun si en muchos momentos la situación interna de la Iglesia diocesana cordobesa fue conflictiva y difícil, nunca llegó al punto de romper con su obispo.

Conviene recordar que mientras Orellana se encontraba preso por las autoridades revolucionarias, el prelado seguía conectado con su diócesis, como lo prueban sus cartas a las carmelitas de Córdoba (TONDA 1973). Además, Orellana era consultado para la resolución de asuntos de administración eclesiástica, como lo hizo la Asamblea del año XIII (AYROLO 2013), e intervenía en el gobierno diocesano, como en la elección como provisor de Benito Lascano 
en $1816 .{ }^{2}$ Pero esto ocurre también en la Diócesis de Salta, donde el cabildo eclesiástico continuó consultando aun en su destierro al obispo Nicolás Videla del Pino, expulsado de su diócesis por el general Belgrano por sus vínculos con el bando realista (AYROLO; CARETTA 2003).

En Córdoba, la noticia del nombramiento de un obispo era recibida gratamente por el clero secular, ya que esto significaba la posibilidad de que los aspirantes a ordenarse consiguieran sus órdenes mayores (AYROLO 2001; AYROLO; CARETTA 2009). De hecho, "entre 1786 y 1792 no hay ordenaciones en la diócesis por no haber obispos" (AYROLO; CARETTA 2009, p. 91). Gabriela Caretta y Valentina Ayrolo han registrado 330 ordenados entre 1780 y 1804 por los obispos del Tucumán, mostrando que "en los años inmediatos a la llegada de un nuevo obispo puede observarse un pico en el número de ordenados que se estabiliza en los años posteriores, lo que indica que muchos esperaban la llegada del pastor para ordenarse" (AYROLO; CARETTA 2009, p. 92). Y demuestran que:

Si consideramos los obispados de San Alberto y Ángel Mariano Moscoso observamos que en los dos casos se da una mediana anual que ronda los 11 clérigos ordenados. Durante el gobierno de San Alberto (1780-1785) se ordenaron 56 clérigos. Durante la administración de Ángel Mariano Moscoso (1793-1804) se ordenaron 130 individuos. [...] En principio podemos afirmar que no hay una caída del número de ordenados y que tampoco, por lo analizado hasta el momento, los clérigos esperaran la sede vacante para ordenarse en otras diócesis [...] (AYROLO; CARETTA 2009, p. 93).

En definitiva, aunque algunos estudios de historia eclesiástica en Argentina han observado en el ámbito rioplatense la debilidad de la figura episcopal en beneficio del clero secular, agravado por las prolongadas vacancias diocesanas, esto no fue así en el caso de Córdoba. En el primer obispado de la región, y uno de los tres existentes al momento del estallido revolucionario, los obispos fueron ejes de la administración diocesana y fuente de legitimidad (MAZZONI 2013). Por ello podemos afirmar que la tarea pastoral diocesana fue importante en el proceso de construcción del espacio eclesiástico-político o político-institucional del obispado cordobés y que la influencia y participación de los obispos en cuestiones eclesiásticas y políticas en el ámbito local tuvo una mayor capacidad de gestión que en otros espacios, como el porteño (AYROLO 2008; MAZZONI 2013).

\section{Consideraciones finales}

A lo largo de este trabajo marcamos las líneas de investigación abiertas a partir de la expansión de la historiografía académica en Argentina en la década de 1990 en torno a una historia centrada en el episcopado entre el periodo tardocolonial y temprano independiente. La historia de la iglesia en nuestro país se desarrolló al calor del diálogo con la historia social, política, cultural y económica

\footnotetext{
2 En 1816, estando Orellana preso en su segundo cautiverio, Benito Lascano fue elegido por el cabildo como provisor de la diócesis. Sin embargo, el obispo Orellana se negó a legitimarlo y redactó un escrito titulado "Justa Defensa", denunciando las disposiciones ilegítimas que el cabildo estaba llevando a cabo en su ausencia. En este caso, Lascano apeló al Congreso para legitimar su nombramiento, y los representantes le aconsejaron dirigirse a Santa Fe a conseguir personalmente la confirmación del obispo en su cargo (AYROLO; MAZZONI 2013).
} 
que contribuyó con innovadoras preguntas al estudio de una institución clave para entender el periodo colonial y la primera mitad del siglo XIX.

Nos focalizamos en el debate en torno a la administración diocesana en las diferentes diócesis rioplatenses. En este sentido, analizamos cómo el gobierno de los obispos, la forma en la que ejercían su autoridad, guardaba en Córdoba relación con lo que ocurría en diócesis de antigua colonización como las del espacio peruano, y poseían una cuota de autoridad mayor que en iglesias "de frontera" como la de Buenos Aires. Como vimos, esta diferenciación se correlaciona con las disímiles trayectorias de ambos espacios. Mientras la diócesis porteña ha sido calificada como una "iglesia de frontera" (DI STEFANO 1997; 2004), la de Córdoba se erigió en un territorio de antigua colonización con un derrotero común a diócesis con una vieja tradición e historia, y con lazos más estrechos con la estructura diocesana indiana, como las altoperuanas (AYROLO 2003; MAZZONI 2013).

En este sentido, la administración diocesana en el obispado de Córdoba del Tucumán, el más antiguo del territorio rioplatense, pone en evidencia el predominio del obispo en el ejercicio del poder en su jurisdicción eclesiástica. La potestad ejercida por los prelados en este espacio constituyó uno de los puntos centrales de la pervivencia de una unidad político-religiosa en el espacio cordobés durante la primera mitad del siglo XIX.

\section{Referencias bibliográficas}

ALBANI, Benedetta. The apostolic see and the world: challenges and risks facing global history. Rechtsgeschichte-Legal History, v. 20, p. 330-331, 2012.

- El matrimonio entre Roma y la Nueva España, historia y fuentes documentales (siglos XVI-XVII). En: BIEÑKO DE PERALTA, Doris y BRAVO RUBIO, Berenise. De sendas, brechas y atajos: contexto y crítica de las fuentes eclesiásticas, siglos XVI-XVIII. México: Secretaría de Educación Pública, 2008, p. 167-184.

AMORES CARREDANO, Juan Bosco. En defensa del rey, de la patria y de la verdadera religión: el clero en el proceso de independencia de Hispanoamérica. En: AMORES CARREDANO, Juan Bosco. Las independencias iberoamericanas ¿Un proceso imaginado? Bilbao: Universidad del País Vasco, 2009, p. 209-234.

ARTOLA RENEDO, Andoni. De Madrid a Roma. La fidelidad del episcopado en España (1760-1833). España: Ediciones Trea, 2013.

El acceso al episcopado en la monarquía hispánica (1789- 1800). En: Los tiempos de Espada: Vitoria y La Habana en la era de las revoluciones atlánticas. Bilbao, España: Servicio de Publicaciones de la Universidad del País Vasco, 2014, p. 23-54.

AYROLO, Valentina. Congrua sustentación de los párrocos cordobeses. Aranceles eclesiásticos en la Córdoba del ochocientos. Cuadernos de Historia, p. 39-66, 2001. 
. Cura de almas. Aproximación al clero secular de la diócesis de Córdoba del Tucumán, en la primera mitad del siglo XIX. Anuario IEHS, v. 16, p. 421-443, 2001.

. Estudios sobre clero iberoamericano, entre la independencia y el Estado-Nación. Salta: CEPIHA, 2006.

- Funcionarios de Dios y de la República. Clero y política en las autonomías provinciales. Buenos Aires: Biblos, 2007.

- La carrera política del clero. Aproximación al perfil político-clerical de algunos hombres del siglo XIX. El caso de los de Córdoba. PolHis, v. 7, p. 100-114, 2011.

. La estela de la Ley de Obispados de 1813 en la administración diocesana. Anuario del Instituto de Historia Argentina, v. 13, p. 1-15, 2013.

- La Provincia-diócesis de Córdoba. Religión y política en la autonomía provincial 1820-1852. En: CARETTA, Gabriela; ZACCA, Isabel. Para una historia de la iglesia. Itinerarios y estudios de caso. Salta: CEPIHA/ UNSa, 2008, p. 37-45.

- Los deberes del Obispo Orellana. Entre la pastoral y la patria, 1810-

1817. En: Catolicismo y política en Córdoba, siglos XIX y XX. Córdoba: Ferreyra Editor, 2010, p. 21-42.

- Representaciones sociales de los eclesiásticos cordobeses de principios del siglo XIX. Andes, v. 11, p. 161-175, 2000.

. Una Iglesia del interior de las Provincias Unidas: Córdoba en la primera 126 mitad del siglo XIX. Jahrbuch für Geschichte Lateinamerikas, v. 40, p. 179-201, 2003.

. Una nueva lectura de los informes de la misión Muzi: la Santa Sede y la iglesia de las Provincias Unidas. Boletín del Instituto Ravignani, v. 14, p. 31-60, 1996.

; BARRAL, María Elena. El clero rural, sus formas de intervención social y su politización (las Diócesis de Buenos Aires y Córdoba en la primera mitad del siglo XIX). Anuario de Estudios Americanos, v. 69, p. 139167, 2011.

; CARETTA, Gabriela. Clérigos seculares del Tucumán entre la colonia y la independencia (1776-1810). En: AGUIRRE, Rodolfo; ENRÍQUEZ, Lucrecia. La iglesia Hispanoamericana de la colonia a la república. México: Editorial Plaza y Valdés-Ediciones Universidad Católica, 2009, p. 45-70.

- Oficiar y gobernar. Apuntes sobre la participación política del clero secular de Salta y Córdoba en la pos-revolución. Andes, v. 14, p. 105-130, 2003.

; MAZZONI, María Laura. De familiar a Obispo de Córdoba. La trayectoria política de Benito Lascano como ejemplo de ascenso en la carrera eclesiástica, 1800-1836. Anuario de la Escuela de Historia Virtual, v. 4, p. 35-56, 2013.

BARRAL, María Elena. De mediadores componedores a intermediarios banderizos: el clero rural de Buenos Aires y la "paz común" en las primeras décadas del siglo XIX. Anuario IEHS, v. 23, p. 151-174, 2009. 
. De sotanas por la pampa. Religión y sociedad en el Buenos Aires rural tardocolonial. Buenos Aires: Prometeo, 2007.

. Disciplina y civilidad en el mundo rural de Buenos Aires a fines de la Colonia. Jahrbuch für Geschichte Lateinamerikas, v. 44, p. 135-155, 2007.

. "Fuera y dentro del confesionario". Los párrocos rurales de Buenos Aires como jueces eclesiásticos a fines del período colonial. Quinto Sol, v. 7, p. 11-36, 2003.

; DI STEFANO, Roberto. Las «misiones interiores» en la campaña de Buenos Aires entre dos siglos: de los Borbones a Rosas. Hispania Sacra, 60, 122, p. 635-658, 2008.

BARRIO GOZALO, Maximiliano. La jerarquía eclesiástica en la España moderna:

Sociología de una élite de poder (1556-1834). Cuadernos de historia moderna, v. 25, p. 17-60, 2000.

BENITO MOYA, Silvano. La Universidad de Córdoba en tiempos de reformas

(1701-1810). Córdoba: Centro de Estudios Históricos "Prof. Carlos S. A. Segreti", 2011.

BRUNO, Cayetano. Historia de la Iglesia en la Argentina. Buenos Aires: Don Bosco, 1970.

CASTAÑEDA DELGADO, Paulino y MARCHENA FERNÁNDEZ, Juan. La jerarquía de la Iglesia en Indias: el episcopado americano, 1500-1850. España: Fundación MAPFRE, 1992.

CONNAUGHTON, Brian. El cura párroco al arribo del siglo XIX: el interlocutor interpelado. En: MAYER, Alicia. Religión y vida cotidiana. El historiador frente a la historia. México: UNAM, 2008, p. 189-214.

CUENCA TORIBIO, José Manuel. Iglesia y Estado a fines del Antiguo Régimen: la elección del episcopado hispano-americano. Anuario de estudios americanos, v. 33, p. 105-143, 1976.

DELLAFERRERA, Nelson. La iglesia diocesana: las instituciones. En: Nueva Historia de la Nación Argentina. Buenos Aires: Academia Nacional de la Historia-Planeta, 1999, p. 385-416. . Los provisores de Córdoba. Cuadernos de Historia, v. 6, p. 69-119, 1996.

DI STEFANO, Roberto. Abundancia de clérigos, escasez de párrocos: las contradicciones del reclutamiento del clero secular en el Río de la Plata (1770-1840). Boletín del Instituto Ravignani, v. 16/17, p. 33-59, 1997.

. El púlpito y la plaza. Clero, sociedad y política de la monarquía católica a la república rosista. Buenos Aires: Siglo XXI, 2004.

. Entre Dios y el César: el clero secular rioplatense de las reformas borbónicas a la Revolución de Independencia. Latin American Research Review, v. 35. n. 2, p. 130-159, 2000.

- Lay Patronage and the Development of Ecclesiastical Property in Spanish America: The Case of Buenos Aires, 1700-1900. The Hispanic American Historical Review, v. 93, n. 1, p. 67-98, 2013. 
. Pastores de rústicos rebaños. Cura de almas y mundo rural en la cultura ilustrada rioplatense. Boletín del Instituto Ravignani, v. 22, p. 7-32, 2000.

. Poder episcopal y poder capitular en lucha: el conflicto entre el obispo Malvar y Pinto y el cabildo eclesiástico de Buenos Aires por la cuestión de la liturgia. Memoria Americana, v. 8, p. 67-82, 1999.

; MARTÍNEZ, Ignacio. Frailes de gorro frigio. La experiencia de la Comisaría General de Regulares en el Río de la Plata (1813-1816). En: Los dominicos insurgentes y realistas, de México al Río de la Plata. Querétaro: Instituto Dominicano de Investigaciones Históricas Miguel Ángel Porrúa, 2011, p. 147-181.

; ZANATTA, Loris. Historia de la Iglesia Argentina. Desde la conquista hasta fines del Siglo XX. Buenos Aires: Sudamericana, 2000.

ENRÍQUEZ AGRAZAR, Lucrecia. Trayectoria política de un obispo español en la revolución americana: Diego Antonio Navarro Martín Villodres, obispo de Concepción (1806-1816). Anuario de Historia de la Iglesia en Chile, v. 23, p. 39-57, 2005.

ENRÍQUEZ, Lucrecia. El Patronato en Chile de Carrera a O'Higgins (1812-1824).

Hispania Sacra, 60, 122, p. 507-529, 2008.

FERNÁNDEZ MELLÉN, Consolación. Iglesia y poder en La Habana: Juan José Díaz de Espada, un obispo ilustrado (1800-1832). Bilbao, España: Universidad del País Vasco; Servicio Editorial, 2014.

FOGELMAN, Patricia. Una cofradía mariana urbana y otra rural en Buenos Aires a fines del periodo colonial. Andes, v. 11, p. 179-207, 2000.

FRASCHINA, Alicia. Mujeres consagradas en el Buenos Aires colonial. Buenos Aires: Eudeba, 2010.

GALLO, Klaus; CALVO, Nancy y DI STEFANO, Roberto. Los curas de la revolución. Buenos Aires: Emecé, 2002.

HERNÁNDEZ GARCÍA, Elizabeth. Una columna fortísima del altar y del trono: Pedro Gutiérrez de Cos, obispo de Huamanga y de Puerto Rico (17501833). Hispania sacra, v. 60, n. 122, p. 531-555, 2008.

LEVAGGI, Abelardo. La Iglesia y sus relaciones con el Estado. En: Nueva historia

de la Nación Argentina, V (1810-1914). Buenos Aires: Academia Nacional de la Historia (Argentina), 2003, p. 313-344.

LIDA, Miranda. Dos ciudades y un dean. Biografia de Gregorio Funes, 17491829. Buenos Aires: Eudeba, 2006.

- Fragmentación política y fragmentación eclesiástica. La revolución de independencia y las iglesias rioplatenses (1810-1830). Revista de Indias, v. LXIV, n. 231, p. 383-404, 2004.

LORANDI, Ana María. Poder Central, Poder Local: Funcionarios Borbónicos en el Tucumán Colonial: Un Estudio de Antropología Política. Buenos Aires: Prometeo Libros Editorial, 2008.

MAEDER, Ernesto J. A. La vida de la iglesia. En: Nueva Historia de la Nacion Argentina. Buenos Aires: Academia Nacional de la Historia, 2003, p. 277-312. 
MALLO, Silvia. Iglesia, valores cristianos y comportamientos: el Río de la Plata a fines del período colonial. Trabajos y comunicaciones, v. 26/27, p. 93-113, 2000.

Sacerdotes y feligreses en el Río de la Plata. La transición del Siglo XVIII al XIX. Estudios e Investigaciones, v. 22, p. 19-35, 1995.

MARTÍNEZ DE SÁNCHEZ, Ana María. Cofradías y obras pías en Córdoba del Tucumán. Córdoba: EDUCC, 2006.

MARTÍNEZ, Ignacio. El 'obispo universal' y sus tenientes. Ingreso de la autoridad papal a las iglesias rioplatenses. 1820-1853. En: Signos en el tiempo,

Rastros en la tierra. Luján: Universidad de Luján, 2011, p. 17-38.

Una Nación para la Iglesia argentina. Construcción del Estado y jurisdicciones eclesiásticas en el siglo XIX. Buenos Aires: Academia Nacional de la Historia, 2013.

MAZÍN GÓMEZ, Óscar. Los espacios agropecuarios como fronteras de la Monarquía Indiana en 1650. Prohistoria, v. 24, p. 21-40, 2015.

MAZZONI, María Laura. El clero regular y el gobierno diocesano en el obispado de Córdoba del Tucumán en la tardocolonia. Aproximación historiográfica a un vínculo difuso. Anuario IEHS, v. 31, n. 1, p. 119-133, 2016.

. La administración diocesana en Córdoba del Tucumán en el periodo tardocolonial en el marco de la legislación eclesiástica de Lima y Charcas. En: ALBANI, Benedetta ; DANWERTH, Otto y DUVE, Thomas. Normatividades e instituciones eclesiásticas en Iberoamérica: Perú, siglos XVI-XIX. Frankfurt, Alemania: Max-Planck-Institut für europäische Rechtsgeschichte, 2015, p. en prensa.

- La gestión diocesana como instrumento de equipamiento eclesiástico del territorio. La administración diocesana de Ángel Mariano Moscoso, diócesis del Tucumán (1788-1804). Folia Histórica del Nordeste, 2015 [en prensa].

Mandato divino y poder terrenal. La administración diocesana en el Obispado de Córdoba, 1778-1836. Tesis doctoral. Universidad Nacional del Centro de la Provincia de Buenos Aires, Tandil, 2013.

- Servidor del trono y del altar. Aproximaciones sobre el reformismo borbónico en América a través del gobierno diocesano del obispo San Alberto, Diócesis del Tucumán (1778-1783). En: SERRANO, Eliseo. De la tierra al cielo. Líneas recientes de investigación en Historia Moderna. Zaragoza: Institución "Fernando el católico" (C.S.I.C.), 2013, p. 309-328. ; GÓMEZ, Fernando. Clero y política en La Rioja en los años veinte del siglo XIX. El Teniente de cura Melchor León de la Barra, de revolucionario a 'reo de alto crimen'. Almanack, v. 9, p. 103-114, 2015.

PAIVA, José Pedro. Os bispos de Portugal e do império 1495-1777. Coimbra: Imprensa da Universidade de Coimbra, 2006.

PEIRE, Jaime. El taller de los espejos. Iglesia e imaginario 1767-1815. Buenos Aires: Claridad, 2000.

PELAGATTI, Oriana. Los capellanes de la guerra. La militarización del clero en el frente oeste de la revolución rioplatense. En: BRAGONI, Beatriz y MATA, 
Sara. Entre la Colonia y la República: Insurgencias, rebeliones y cultura política en América del Sur. Buenos Aires: Prometeo, 2008, p. 193-216.

PEÑA, Gabriela. La integración de los indios en la iglesia cordobesa. Siglos XVI y XVII. Investigaciones y Ensayos, v. 44, p. 365-380, 1994.

PÉREZ PUENTE, Leticia. El obispo. Político de institución divina. En: MARTÍNEZ LOPEZ-CANO, Pilar. La Iglesia en Nueva España. Problemas y perspectivas de Investigación. México: UNAM-Publicaciones digitales del IIH, 2012, p. 151-184.

ROJAS INGUNZA, Ernesto. El báculo y la espada: el obispo Goyeneche y la iglesia ante la iniciación de la República, Perú 1825-1841. Lima: Instituto Riva Agüero, 2007.

ROMERO, José Luis. La biografía como tipo historiográfico. En: La vida histórica. Buenos Aires: Siglo XXI, 2008, p. 104-117.

SALVADOR AGUIRRE, Rodolfo. Historia social de la Iglesia y la religiosidad novohispanas. Tendencias historiográficas. Fronteras de la Historia, v. 15, 1, p. 135-156, 2010.

SÁNCHEZ PÉREZ, Emiliano. El obispo Nicolás Videla y el General Belgrano. 18121819. Hispania Sacra, v. 66, n. 133, p. 133-177, 2014.

TAYLOR, William. Ministros de lo sagrado. Sacerdotes y feligreses en el México del siglo XVIII. México: El colegio de México y El colegio de Michoacán, 1999.

TONDA, Américo. El Obispo Orellana y la Revolución. Buenos Aires: Academia Nacional de la Historia, 2009.

El Obispo Orellana. Sus cartas a las carmelitas de Córdoba. Rosario: Pontificia Universidad Católica Argentina-Facultad de Humanidades de Rosario, 1973.

Ocampo, Orellana y los Betlemitas de Córdoba. Investigaciones y Ensayos, v. 13, p. 493-518, 1973.

TROISI-MELEAN, Jorge. Redes, Reforma y Revolución: Dos franciscanos rioplatenses sobreviviendo al siglo XIX (1800-1830). Hispania Sacra, v. 60, n. 122, p. 467-484, 2008.

. Los franciscanos de la provincia de Asunción en la transición del periodo colonial al independiente (1780-1820). En: AYROLO, Valentina. Estudios sobre clero iberoamericano, entre la Independencia y el EstadoNación. Salta: CEPIHA, 2006, p. 115-132.

URQUIZA, Fernando. Etiquetas y conflictos: el obispo, el virrey y el cabildo en el Río de la Plata en la segunda mitad del siglo XVIII. Anuario de Estudios Americanos, v. L, n. 1, p. 55-100, 1993. 